In this chapter we describe strategies teaching and learning centers can use in partnering with programs to conduct action-oriented assessment projects. We illustrate these strategies with examples from an evaluation of a social engagement requirement for art and design students.

\title{
Partnering with Teaching and Learning Centers for Curricular Assessment: A Case
}

\section{Study of Best Practices}

Tracy Bartholomew, Mary C. Wright, Charlie Michaels

In some institutions, there is little interaction between those who collect and report assessment data and those who focus on improving teaching and learning. Teaching centers are in a unique position to bridge this gap by partnering with faculty and administrators on curricular assessment (Wright, Goldwasser, Jacobson, and Dakes 2017). Research on faculty and administrator support for institutional effectiveness activities suggests why teaching centers are well positioned to facilitate these endeavors. Faculty are more likely to participate in assessment activities if they believe these activities stem from an internally driven need (as opposed to external pressures) and if they have personal involvement over their design and implementation (Welsh and Metcalf 2003a). An emphasis on the applications of assessment data_ or "real results arising from instruction and efforts to improve" — is also critically important to achieve buy-in (Welsh and Metcalf 2003a, 41). Teaching centers can play important roles in fostering all of these dynamics. Staff at teaching centers typically have much experience working with academic administrators and faculty on critical assessmentrelated tasks, such as defining local instructional needs, helping faculty work collaboratively, facilitating conversations and events that will prompt curricular enhancement, and providing resources to support follow-up and implementation of changes (Cook, Meizlish, and Wright 2011).

This is the author manuscript accepted for publication and has undergone full peer review but has not been through the copyediting, typesetting, pagination and proofreading process, which may lead to differences between this version and the Version of Record. Please cite this article as doi: $\underline{10.1002 / t 1.20299 .}$.

This article is protected by copyright. All rights reserved. 
In this chapter, we offer specific strategies teaching and learning centers can use in partnering with programs to conduct action-oriented assessment projects. We will illustrate these strategies with examples from an evaluation conducted by the University of Michigan (U-M) Center for Research on Learning and Teaching of a social engagement requirement for undergraduate art and design students at the Stamps School of Art \& Design. The best practices for encouraging administrative and faculty support identified in Welsh and Metcalf's research (2003a, 2003b) will serve as a framework for describing our approach to the project.

\section{CRLT's Assessment and Evaluation Projects}

The University of Michigan's Center for Research on Learning and Teaching (CRLT) has a long history of work on both curricular reform and assessment. We emphasize this work because it can lead to significant long-term improvement for student learning. Moreover, the involvement of the teaching center provides an opportunity to raise issues of pedagogy and pedagogical content knowledge in the context of the disciplinary and intellectual concerns of the faculty. We work with faculty and administrators in all 19 schools and colleges at U-M as well as with the Provost's Office and other units on assessment and evaluation of student learning outeomes and experiences. Our assessment and evaluation projects have three defining charaeteristics:

- The focus is on improving U-M student learning experiences or outcomes, directly or indirectly.

- We work in collaboration with faculty and academic units, guided by their learning goals.

- Projects are action-oriented, with the objective of generating evidence that is useful for faculty and administrators to improve courses or curricula. Some of this work is published, but most is designed to be shared in venues such as faculty retreats or department meetings, where key curricular decisions get made. 


\section{Stamps Social Engagement Requirement}

In 2006, the Penny W. Stamps School of Art \& Design at the University of Michigan initiated a new social engagement graduation requirement for undergraduates, requiring them to enroll in a specially-designated engagement studio course in which students interact with a community outside the university. The mission of the social engagement requirement is to enable students to "understand the meaning and impact of their work - 'engaging' them in a curriculum that builds understanding of the agency they possess as artists and designers and guiding them in determining how to use that agency to impact the world around them" (Social Engagement at Stamps - Mission, Objectives, and Criteria). Faculty identified six key student learning outcomes for the requirement.

- Use ageney as artists and designers to develop and initiate engaged projects that have creative or social impact.

- Be comfortable and confident working in and forming connections with diverse communities, populations, situations, and places outside their own lived experiences.

- Find creative ways to challenge, seek solutions to, or take action toward critical social issues

- Use critical analysis skills to understand, analyze, and articulate complex social systems.

- Be able to work collaboratively with community partners on projects that are reciprocally developed and carried through, recognizing that they and their partners have both needs and assets to share.

- Be able to identify and make use of resources that students and their community partners have to offer.

\section{Social Engagement Requirement Evaluation Plan}

In 2015, the Stamps School engaged CRLT to conduct an evaluation study of the requirement. The key purposes of the evaluation were to assess learning gains regarding key 
outcomes identified by the School for social engagement courses, gather stories and data for internal and external use by the School, and do a more intensive one-time study about impacts of social engagement courses to establish an in-house process for regular feedback about these courses.

Together with the Stamps Engagement Course Coordinator, CRLT developed seven questions toguide the study.

1. Are the existing outcomes set for the requirement the "right" outcomes, from the perspective of faculty and students?

2. What is the impact of the requirement on student learning?

3. When do students tend to take their first engagement course? What proportion of students surpass the requirement, taking more than one course? Is the requirement taken at the same rate and approximately the same time by students of varying backgrounds?

4. Among those with longer-term perspectives on the requirement (seniors and alumni), should there be a requirement, and if so, why? What longer-term outcomes do seniors and alumni report? What recommendations do seniors and alumni have for enhancement of the requirement?

5. Among students who were enrolled in an engagement course in Fall 2015, what do they perceive as common strengths and suggestions?

6. Among select community partners, what do they perceive as the key strengths and suggestions of the requirement implementation at their sites?

7. What questions might be productively implemented in an ongoing internal evaluation system of the requirement, conducted by Stamps faculty and/or staff?

To answer these questions, CRLT used a mix of qualitative and quantitative measures, presented in Table 1. 
(Insert Table 1 Here)

\section{Strategies for Enhancing Administrative and Faculty Support}

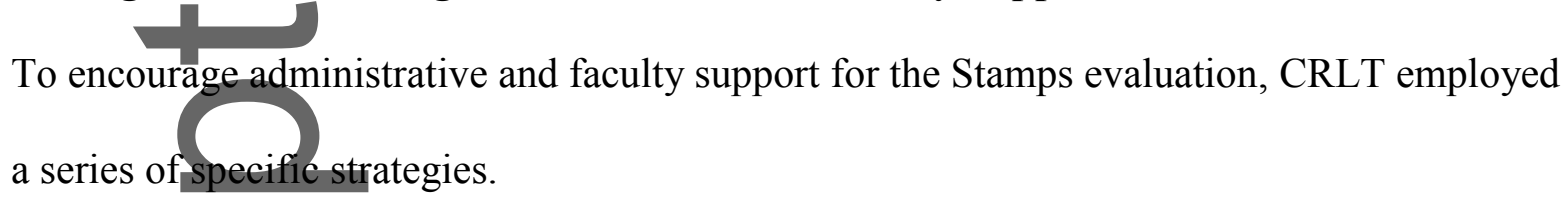

Promote the notion that that the primary reason for implementing institutional effectiveness activities is to improve the institution's programs and services.

Administrative and faculty support for carrying out assessment activities, and by extension, for using the results of assessment for curricular improvement, depends on the sense that "the primary motivation" for these activities is for improvement (Welsh and Metcalf 2003a, 40). In the Stamps project, we were sensitive to the fact that we would be entering classrooms to gather feedback from students on their particular course and instructor. Therefore, before conducting the SGIDs, we met with each instructor to learn about the goals of their course and ask if they wanted us to solicit student feedback on any specific items. For example, the SGID might include a question about how well the assigned readings prepared students for their community engagement work. After collecting the student feedback, we met with each instructor again to share our findings, answer their questions, and get their permission to incorporate the findings (anonymized and aggregated to maintain instructor and student confidentiality) into the larger evaluation report. We also followed up with instructional resources when requested.

Further, in designing the evaluation study, we kept the goal of improvement in the forefront by employing questions and methods that not only aimed to measure the impact of the requirement but also to understand how the program was or was not helping students achieve the goals of the requirement.

Ensure personal involvement in institutional effectiveness activities. Welsh and Metcalf $(2003 a, 40)$ found that faculty support for institutional effectiveness efforts is more 
likely "if they and their colleagues lead, own and participate in the process." At CRLT, we are in the enviable position of having administrators and faculty approach us to assess their programs (instead of the other way around). Despite this, we make an intentional effort to involve administrators and faculty in as many stages of the evaluation project as possible. First, we design the evaluation plan in collaboration with administrators or faculty to make sure it reflects their questions of interest. For example, CRLT staff worked together with the Stamps Engagement Course Coordinator to design the questions for the evaluation. We then held a meeting with the Stamps administrators and engagement course faculty instructors to discuss the questions and preliminary ideas for addressing the questions. We also involved the administrators and faculty in the data interpretation phase by scheduling a meeting to present the results and asking questions such as:

- What did you learn from the report?

- What was surprising?

- What is missing?

- What else should we have asked?

- What do you still want to know or explore?

- Does this study make a difference?

In our presentation of evaluation results, we also make sure to highlight success stories and good news to acknowledge the involvement and contributions of the administrators and faculty.

Promote an outcomes-oriented perspective on quality. An institutional emphasis on outcomes, or results that illustrate if, how, and what students are learning, is also critical to faculty support of institutional reform initiatives (Welsh and Metcalf 2003a). In the protocols we developed for the SGIDs and the student focus group, we asked students to describe if and how the social engagement courses helped them achieve the outcomes and what changes 
could be made to help them learn better. Similarly, we asked the alumni to identify which of the six outcomes they felt resulted because of their social engagement experiences in Stamps and ways in which their preparation could have been enhanced to improve their learning for those outcomes. We also asked the engagement faculty to identify which of the six outcomes were mostrelevant to their own course. In addition, in our discussion with the Stamps seniors, we asked the students whether they believed the social engagement outcomes were clear, appropriate, and applicable to their experiences. Through this data collection approach, we were able to provide the School with information on what the appropriate intended outcomes for the social engagement courses should be, the longer-term outcomes resulting from the experiences, which pedagogical approaches supported those outcomes, and suggestions for enhancing communication and student achievement of those outcomes.

In addition, our analysis of SERU data provided information on the impact of the Stamps requirement on outcomes associated with participation in an engagement experience, for example the ability to work collaboratively across difference and the ability to employ critical perspective-taking.

\section{Employ effective communication strategies about the process and the results.} Participants in Welsh and Metcalf's (2003a) study emphasized the importance of communication in order to develop faculty and administrative support for institutional effectiveness activities. We have likewise found communication critical to the success of our evaluation projects. For example, when it is time to share the results of an evaluation with the client, we hold a face-to-face meeting with the key stakeholders where we review key findings, answer questions, and offer suggestions for responding to the findings if requested. Another recommended practice is to share and get feedback on preliminary results where appropriate or useful. For example, following the SGID sessions, we met with each 
individual instructor to review our findings and discuss how we would incorporate the findings into the final report.

In producing the written report, we create an executive summary and include descriptive figures, table labels, and data visualizations such as icon arrays, dot plots, slope graphs, and quotes to highlight the key findings from the evaluation (Evergreen 2014, 2017). Figures 1 and 2 are two examples of how we used visuals to communicate main findings from our evaluation.

[Insert Figures 1 and 2 Here]

\section{Results of Our Partnering Approach}

By taking a collaborative approach to assessment that utilizes the best practices for enhancing administrative and faculty support, CRLT has been able to carry out assessment projects that generate evidence programs can and do use to inform decisions about teaching, curriculum, and student learning. For example, based on the findings from CRLT's evaluation of the Stamps social engagement requirement, the School's administrators concluded that students need a better understanding of the goals of the requirement and how those goals fit into the overall curriculum of the School. The School is therefore in the process of restructuring one of the program's foundational courses to include more content that will prepare students for their social engagement experiences. The evaluation results also pointed towards a need to offer a wider variety of course topics across art and design, a wider variety of approaches to social engagement (for instance, working with a partner organization or community vs. working in a more interventionist way), and a wider variety of partners. School administrators are also considering different options for the on-going evaluation of the requirement, such as using targeted questions on end-of-course evaluations, or implementing some form of pre-test/post-test assessment.

\section{References}


Cook, Constance E., Deborah S. Meizlish, and Mary C. Wright. 2011. "The Role of a Teaching Center in Curricular Reform and Assessment." In Advancing the Culture of Teaching on Campus: How a Teaching Center Can Make a Difference, edited by

Constance E. Cook and Matthew Kaplan, 121-136. Sterling, VA: Stylus.

Evergreen, Stephanie D. H. 2014. Presenting Data Effectively: Communicating Your Findings for Maximum Impact. Thousand Oaks, CA: Sage.

Evergreen, Stephanie D. H. 2017. Effective Data Visualization: The Right Chart for the Right Data. Thousand Oaks, CA: Sage.

Welsh, John F., and Jeff Metcalf. 2003a. "Cultivating Faculty Support for Institutional Effectiveness Activities: Benchmarking Best Practices.” Assessment \& Evaluation in Higher Education, 28(1), 33-45.

Welsh, John F., and Jeff Metcalf. 2003b. "Faculty and administrative support for institutional effectiveness activities. A bridge across the chasm?" The Journal of Higher Education, 74(4), 445-468.

Wright, Mary C., Molly Goldwasser, Wayne Jacobson, and Christopher Dakes. 2017. "Assessment from an Educational Development Perspective." To Improve the Academy, 36, 39-49. doi:10.1002/tia2.20051

TRACY BARTHOLOMEW was a research associate at the Center for Teaching and Learning at the University of Michigan. She is now Director of the Center for Teaching, Learning, and Assessment at the University of the Arts in Philadelphia. Her research interests encompass outcomes-based assessment and the use of performance-based assessments to measure student learning.

MARY C. WRIGHT is Director of the Sheridan Center for Teaching and Learning and an Adjunct Assistant Professor of Sociology at Brown University. Her research interests include 
assessment of STEM teaching and learning innovations, evaluation of educational development services, and graduate student professional development.

CHARLIE MICHAELS is Assistant Director of the Center for Socially Engaged Design at the University of Michigan College of Engineering. He is a visual artist by training who specializes in the integration of socially engaged experiential learning components into art and design curricula.

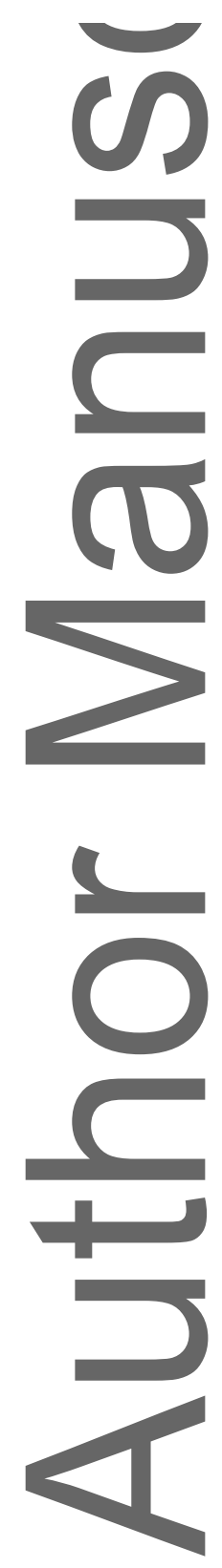


Table 1. Data Sources and Methods Used in Stamps Social Engagement Evaluation

Question Data Source $\begin{aligned} & \text { Description of Method } \\ & \text { In a brief interview, CRLT asked faculty to identify the 3-4 social } \\ & \text { engagement outcomes most relevant to their course. }\end{aligned}$
distributed to all undergraduates in March-June 2015 by the U-M Office
of Budget and Planning. Using questions from the survey that
approximately mapped onto the Stamps social engagement learning
outcomes, CRLT compared the responses from Stamps students who had
completed the requirement to those from Stamps students who had not
yet completed the requirement.

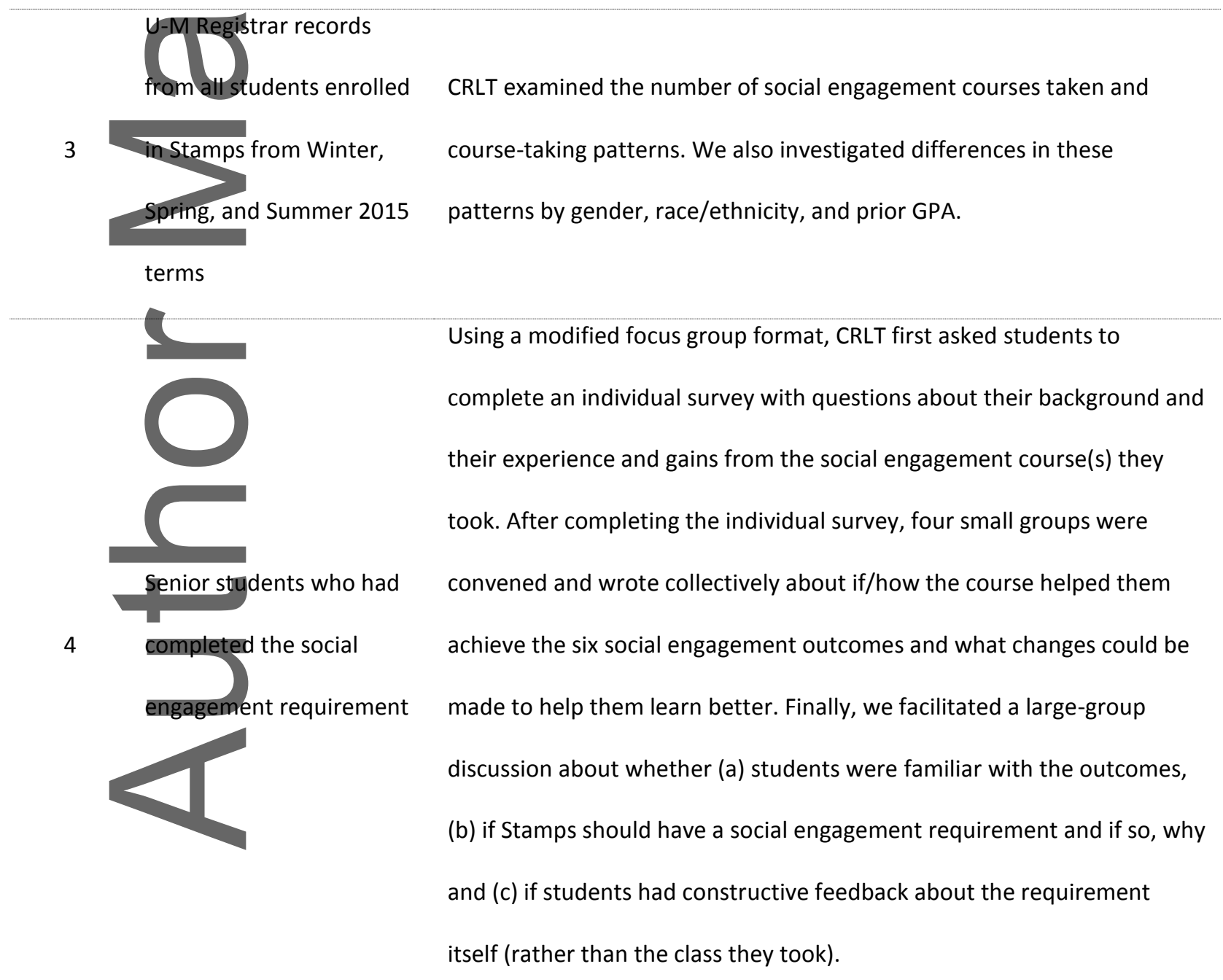

This article is protected by copyright. All rights reserved. 
CRLT led a focus group with local alumni about the impact of the social

\begin{tabular}{|c|c|c|}
\hline 4 & Stamps alumni & $\begin{array}{l}\text { engagement course on their learning and current work. We also asked for } \\
\text { suggestions for improving the requirement. }\end{array}$ \\
\hline 5 & $\begin{array}{l}\text { rrently } \\
\text { an } \\
\text { t course }\end{array}$ & $\begin{array}{l}\text { CRLT conducted a modified Small-group Instructional Diagnosis (SGID) in } \\
\text { the four engagement studio courses offered in Fall 2015. In a 20-25- } \\
\text { minute feedback session during which the instructor was not present, we } \\
\text { asked students to report on key strengths and suggestions for the course } \\
\text { as a whole, as well as for each of the learning outcomes identified by the } \\
\text { instructor. These questions were discussed in small groups and reported } \\
\text { out in large groups. }\end{array}$ \\
\hline 6 & ity partners & $\begin{array}{l}\text { CRLT conducted phone interviews with community partners about the } \\
\text { perceived impact of the social engagement course on Stamps students' } \\
\text { learning, key strengths of the program, and suggestions for future } \\
\text { implementation. }\end{array}$ \\
\hline 7 & tion banks & $\begin{array}{l}\text { CRLT identified sample questions related to the social engagement } \\
\text { outcomes from the existing item bank made available through the U-M } \\
\text { Office of the Registrar for course evaluations. CRLT also researched scales } \\
\text { developed and used by other service-learning programs. }\end{array}$ \\
\hline
\end{tabular}

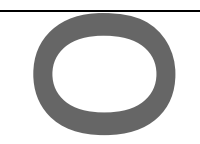

Figure 1. The use of icons and different colors for the alumni and seniors illustrate their perceptions of how well the social engagement requirement addresses each of the desired program outcomes

Figure 2. Dot plots communicate the impact of the social engagement courses on the skills and knowledge students need to work collaboratively in diverse communities

This article is protected by copyright. All rights reserved. 